\title{
Correspondence
}

To the Editors:

\section{Optimal thermal environment in a neonatal cot}

\author{
Sri Lanka Journal of Child Health, 2002; 31: 130
}

Thank you for publishing the above article in your esteemed journal. Subsequent to the publication I have received 2 important communications from Secretary, Ministry of Health, Nutrition and Welfare and Director Maternal and Child Health, Department of Health Services. I am attaching the 2 letters for your perusal and publication in your journal as it has been proposed in these letters to redesign the neonatal cot with the help of the SLCP. I propose either the SLCP or the Perinatal Society of Sri Lanka to proceed on this matter.

\section{Dr Ajith Amarasinghe}

Consultant Paediatrician

1) The first letter is dated 16th May, 2002 and is sent by Dr Reggie Perera, Secretary, Ministry of Health, Nutrition and Welfare to Dr Manil Fernando, DOG (PHS) with copies to Director FHB and Dr A Amarasinghe.

\section{Optimal Thermal Environment in a Neonatal Cot}

Annexed please see a copy of a research article by Dr A Amerasinghe, Paediatrician, B. H. Hambantota, appearing in the current issue of the journal of Child Health. I would like to draw your attention to the following:

- The article points out that an instruction manual is not given with the cots supplied by the FHB.

- It points out that the voltage of the electric bulbs have to be chosen according to the environmental temperature and the weight of the neonates.

- $\quad$ For operating temperature $20^{\circ} \mathrm{C}$ or below it appears that the cot may have to be redesigned.

Please take necessary action and report.
2) The second letter, dated 3rd June, 2002 was written by the Director $(\mathrm{MCH})$ to the Secretary Health, Nutrition and Welfare through DDG (PHS) with copies to Dr A Amarasinghe and Dr Mrs Hiranthi Wijemanne -UNICEF.

\section{Optimal Thermal Environment in a Neonatal Cot}

This has reference to your letter No. PAl DDG(PHS)II/FHB/62/2000 dated 24 May 2002 on the above research article. I wish to congratulate $\mathrm{Dr} A$ Amarasinghe and his team for the useful research done regarding the local Neonatal Cot (copy attached).

Going back in history this cot was designed by the Kandy hospital staff and the Engineering Faculty Peradeniya and used in the Teaching Hospital Kandy for the last 17 years or even more.

It was shown to Dr Mrs Hiranthi Wijemanne (UNICEF \& FHB staff). UNICEF was willing to fund the cost of the cot to be used in hospitals at all levels.

This was done about 15 years ago and the supply has been continuing with minor changes up to date. There is a big demand by the paediatricians and so far we have had no adverse feed backs.

This is produced at Peradeniya and the cost is about Rs. 9000/- only.

The research findings are very good and useful.

I shall be grateful if a committee is appointed with paediatrician Dr A Amarasinghe at the College of Paediatricians and FHB to redesign the neonatal cot using the recommended alterations and also write the guidelines for the use of the cot. 
